Int. J. Dev. Biol. 56: 39-48

doi: $10.1387 / \mathrm{ijdb} .113442 \mathrm{jm}$

\title{
Planarian embryology in the era of comparative developmental biology
}

\author{
JOSÉ M. MARTÍN-DURÁN, FRANCISCO MONJO and RAFAEL ROMERO* \\ Universitat de Barcelona, Departament de Genètica, Barcelona, Spain
}

\begin{abstract}
During the last decade, the field of evolutionary developmental biology (evo-devo) has emerged as a major research discipline in modern biology and an essential approach to understanding evolutionary relationships in the animal kingdom. At the same time, planarians have become a useful and important model with which to address basic questions regarding the molecular and cellular basis of regeneration, tissue repair and stem cells in adult organisms. Nevertheless, little attention has been paid to their embryonic development, even though this provides a unique opportunity for studying how molecular developmental mechanisms are redeployed during adult regeneration or the independent losses of spiral cleavage that took place in different lophotrochozoan lineages. In this paper, we review the most relevant works on planarian embryos from a historical point of view. In doing so, we highlight the questions that have recurrently intrigued researchers, most of which remain unanswered. Finally, we present a comprehensive scenario for planarian embryogenesis in an attempt to provide a testable hypothesis that will help to bridge the gap between this divergent mode of development, the ancestral canonical spiral cleavage, and adult planarian regeneration.
\end{abstract}

KEY WORDS: planarian, embryogenesis, regeneration, evo-devo, gastrulation

\section{Introduction}

The rise of modern molecular evolutionary developmental biology highlighted the conservation of processes and developmental genes among classic model organisms. In the light of new molecular phylogenies, many animals that had long been neglected emerged as key taxa in the study of metazoan ontogeny and phylogeny. Within this scenario, it is striking that little interest has been shown in the embryonic development of Platyhelminthes, especially given that they exhibit various morphological traits (blind gut, simple centralized nervous system, simple eye, etc.) that make them interesting in the context of understanding animal evolution. Triclads, commonly referred to as planarians, have been the most well studied group of flatworms, particularly because of their amazing adult regenerative capabilities.

Planarians are free-living organisms that are found in marine, freshwater and land habitats. They are bilateral worms, with an anteroposteriorly elongated and dorsoventrally flattened body, which can range from a few millimeters to several centimeters long. The model species Schmidtea polychroa (Fig. 1A) is a typical and abundant inhabitant of rivers and lakes in Europe, is about a centimeter long, with dark brown coloration, and exhibits sexual reproduction. Its gross anatomy consists of a head with a pair of eyes and sensory organs (auricles) in the anterior part of the body, a pharynx in the central region, and a posterior copulatory apparatus.

In general, sexually reproducing planarians are hermaphroditic. The reproductive system comprises a male and a female gonad (testis and ovaries, respectively), and the copulatory apparatus. All these components, including germ cells, develop from neoblasts (adult somatic stem cells located in the parenchyma (Shibata et al., 2010)) through epigenesis. The most remarkable feature of this organ system is that the female gonad is heterocellular, which means that female gametes and yolk nutrients are produced in different organs, namely ovaries and yolk glands. Thus, these two elements are segregated into two different cell types (i.e. oocytes and yolk cells). Eggs with this type of organization are called ectolecithic eggs. After mating, several fertilized oocytes and multiple yolk cells are gathered into the atrium of the copulatory apparatus and protected by a dark hard eggshell. This egg capsule is then laid and attached to the ground via a stalk (Fig. 1B).

As Platyhelminthes, planarians belong to the super-phylum Spiralia (sensu Giribet et al., 2000), which includes all organisms in which quartet-spiral cleavage is the ancestral mode of development (Fig. 1C). Platyhelminthes were historically divided into two major groups, according to the organization of the egg: Archoophora, a paraphyletic group comprised of the most basal

*Address correspondence to: Rafael Romero. Universitat de Barcelona, Departament de Genètica, Avda. Diagonal 643, E-08028 Barcelona, Spain.
Tel: +34-934-035301. Fax: +34-934-034420. e-mail: rromero@ ub.edu

Final, author-corrected PDF published online: 16 March 2012

ISSN: Online 1696-3547, Print 0214-6282

(C) 2012 UBC Press

Printed in Spain 
groups, with endolecithal zygotes exhibiting the ancestral quartetspiral cleavage; and Neoophora, a monophyletic clade comprised of all groups of flatworms with ectolecithal eggs and heterocellular female gonads (Fig. 1D) (Westblad, 1948). Planarians therefore belong to the latter. The presence of yolk outside the zygote, and therefore the embryo, constrains development. Different strategies have evolved to ensure that the nutrients eventually end up within the developing embryo in neoophoran Platyhelminthes, and the strategy exhibited by planarians is among the most impressive.

\section{The study of planarian embryogenesis}

The gap in the knowledge and understanding of the embryonic development of Platyhelminthes compared to what is known about their taxonomy, morphology and regenerative capability is remarkable. The reasons for this are directly linked to the biology and life cycle of these organisms: fertilization is strictly internal in most of the species; the embryos are usually protected by hard and dark eggshells that obstruct the in vivo visualization of development; and last but not least, ectolecithal eggs strictly require yolk cells for their development, hindering their manipulation (Galleni and Gremigni, 1982). Nevertheless, in contrast to the situation for other minor groups of flatworms, there has been a more or less continuous stream of studies dealing with planarian embryonic development since the end of the 19th century.

\section{First studies: the foundations}

The earliest reports on planarian embryogenesis date back to the mid 19th century (Kölliker 1846, Knappert 1865, 1866). Despite using simple techniques, they described some of the basic traits of planarian embryonic development. However, many of their descriptions are not that accurate, and in general, the following authors are considered to be the pioneers of planarian embryology: the Russian Elias Metschnikoff (1883), the Japanese Isao lijima (1884) and the French Paul Hallez (1887). Using the freshwater planarians Schmidtea polychroaand Dendrocoelum lacteum as model systems, they gave a comprehensive and realistic description of the embryogenesis of planarians.

Their observations were particularly thorough in early stages of development. Both species lay egg capsules with several zygotes, which are surrounded by a large number of yolk cells arranged in a radial pattern. Soon after cleavage begins, those yolk cells in direct contact with each zygote fuse and form a syncytium, in which blastomeres will continue dividing (Fig. 2A). During this phase, blastomeres lose contact and disperse within the yolk-derived syncytium due to the pressure created by more fusing yolk cells (Fig. 2B-C). Cleavage is complete and more or less equal. According to Hallez (1887) the canonical quartet-spiral pattern is apparent up to the 8-cell stage. However, this observation has not been confirmed (Mattiesen 1904). Blastomeres move around the yolk syncytium until a certain number of blastomeres is reached. At this point, they adopt a distribution that leads to the establishment of the three main germ layers. Some of the blastomeres migrate to the outer limit of the yolk-derived syncytium, and form a thin ciliated primary epidermis that corresponds to the ectoderm (Metschnikoff 1883, Hallez 1887). At the same time, other blastomeres group together in the center of the syncytium, then move to the periphery, and make contact with the embryonic epidermis (Fig. 2D). They develop into a transient embryonic pharynx (lijima, 1884; Hallez, 1887), which at its inner end is in contact with a group of four thin cells that enclose a primary cavity, the transient embryonic intestine. These cells, together with the embryonic pharynx, constitute the endomesoderm of the embryo. The rest of the blastomeres remain in the yolk-derived syncytium. According to Metschnikoff (1883) and lijima (1884) these cells are the mesoderm, whereas Hallez (1887) refers to them as migrating cells, and not mesoderm, since all definitive organs develop from them. The primary epidermis, embryonic pharynx and migrating cells comprise the basic elements of the transient yolk-feeding embryo (Fig. 2E).

The embryonic pharynx is required to swallow the maternally supplied yolk cells. As a consequence, the transient intestine is filled with nutrients, the embryo swells up, and the original yolkderived syncytium with the remaining blastomeres is reduced to a thin peripheral layer. After eating, the embryonic pharynx closes and degenerates, and the definitive organs arise from the migrating cells (Metschnikoff, 1883; lijima, 1884; Hallez, 1887). This late phase of development is not as well described and there are some controversies between authors. For instance, while Metschnikoff (1883) states that the definitive gut arises from some ingested yolk
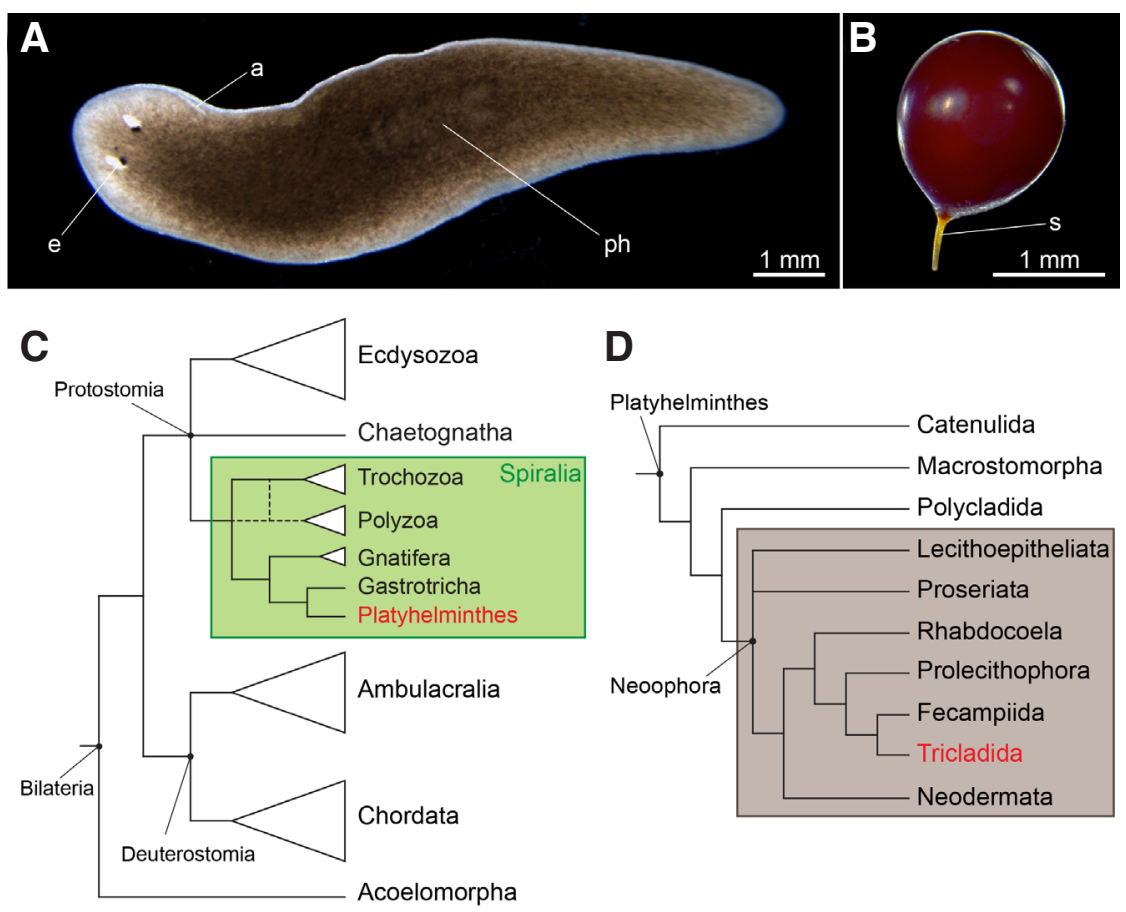

D

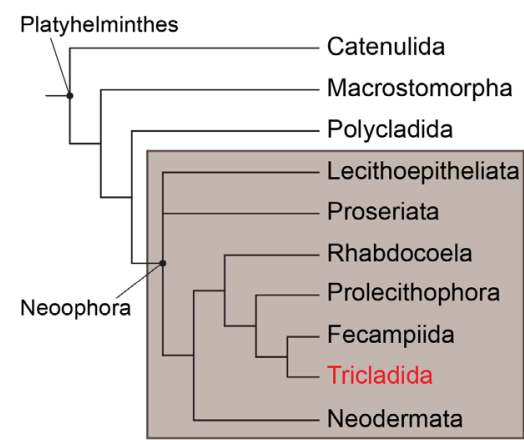

Fig. 1. General morphology and phylogenetic position of planarians. $(\mathbf{A}, \mathbf{B})$ External appearance of a sexually mature adult of the freshwater species Schmidtea polychroa, and an embryonic capsule of the same species, respectively. (C) Phylogenetic position of the phylum Platyhelminthes within bilaterian animals, based on Hejnol et al., 2009 and Hejnol 2010. (D) Phylogenetic position of the order Tricladida within Platyhelminthes, based on Littlewood 2008. a auricle, e eye, ph pharynx, s stalk. 

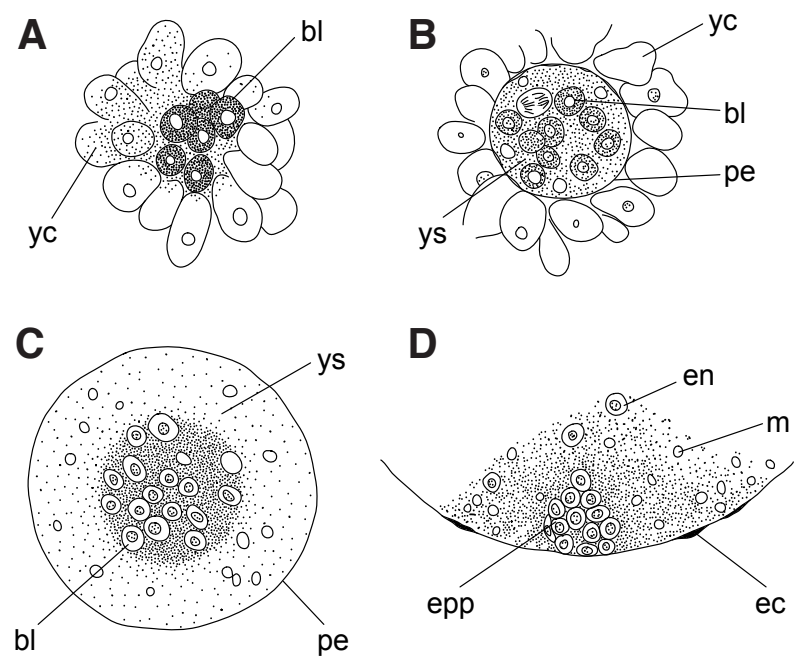

Fig. 2. Early development of planarians. (A-D) Cleavage, formation of the yolk-derived syncytium and early differentiation of the transitory organs of the yolk-feeding embryo (based on lijima 1884). (E) Basic organization of the yolk-feeding embryo at the beginning of the ingestion of the maternally-supplied yolk cells (based on Metschnikoff 1883). Drawings are not to scale. bl, blastomeres; ec, ectoderm; ep, embryonic pharynx; epp, embryonic pharynx primordium; en, endoderm; m, mesoderm; pe, primary epidermis; ti, temporary intestine; yc, yolk cells; ys, yolk-derived syncytium.

cells, Hallez (1887) argues that it is also formed by migrating cells.

These early descriptions represent the basis for every subsequent study regarding planarian embryogenesis. Despite the fact that these authors dealt with a divergent mode of development, they tried to find a comparative framework in which their observations made sense, thereby giving the name of ectoderm, mesoderm and endoderm to structures that are relatively unlike the typical germ layers.

\section{First half of the 20th century}

The first work published on planarian embryos in the new century was conducted by American researchers (Bardeen 1902, Curtis 1902, 1905, Stevens 1904). Using two American freshwater species, Girardia tigrina and Cura foremanii, these studies present general descriptions of their embryonic development (Stevens 1904), but also focus on particular questions regarding planarian embryogenesis, such as the origin of the definitive cell types (Bardeen 1902) and the relationship between the embryonic and the adult pharynx (Curtis 1902, 1905). Furthermore, the work by
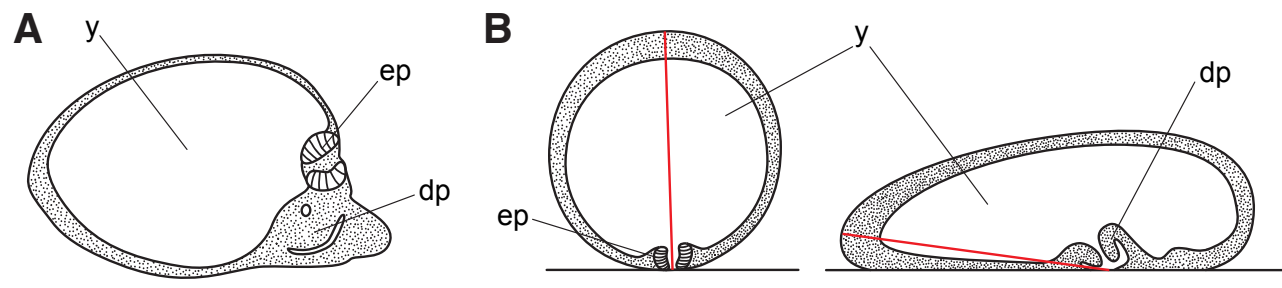

Fig. 3. Alternative hypothesis about the relationship between the embryonic pharynx, the definitive pharynx and the axial identities of the embryo. (A) The embryonic pharynx occupies a dorso-posterior position when the definitive organs start to be formed (modified from Curtis 1902). The definitive pharynx forms ventrally and both structures coexist for a while. (B) The embryonic pharynx develops in the ventroposterior region of the embryo, and after yolk ingestion is superseded in the same location by the definitive pharynx (drawings based on Hallez 1887). According to this latter hypothesis, the radial symmetry of the primary embryo is, at the same time, the future anteroposterior and dorsoventral axes (red line in B). dp definitive pharynx, ep embryonic pharynx, y yolk.
Bardeen (1902) was the first attempt to manipulate planarian embryos in order to experimentally compare the regenerative capacity of the embryo and adult.

The data presented by these authors did not considerably change the classic model for the development of planarians. However, their interpretation of the early stages (i.e. cleavage and formation of the yolk-feeding embryo) varied to a great extent. Unlike previous reports, these authors argued that there is not true segregation of the germ layers, since the definitive organs have their origin in the migrating embryonic cells, which are in fact the only true germ layer (Stevens 1904). Therefore, planarians do not exhibit real gastrulation. This idea was accepted in the majority of subsequent studies on planarian embryos, although it should be considered one of the most important open questions regarding this divergent mode of development (discussed below).

Back in Europe, Mattiesen (1904) presented a detailed description of the embryonic development of Planaria torva and reexamined previous observations of $D$. lacteum and $S$. polychroa. His work raised questions regarding embryonic polarity and how the transient embryonic pharynx is related to the definitive pharynx. The author concluded that the embryonic pharynx develops on the ventral side of the embryo and that after yolk ingestion the definitive pharynx develops at the site of the embryonic pharynx (Fig. 3A). However, his contemporaneous American colleagues assumed a dorsal position for the embryonic pharynx, the definitive pharynx being formed on the ventral side of the embryo before the complete disappearance of the embryonic pharynx (Fig. 3B) (Curtis 1902, Bardeen 1902, Stevens 1904). This controversy caused intense debate (Curtis 1905), and despite the fact that subsequent authors have tended to adopt Mattiesen's interpretation, the issue remains unresolved.

Fulinski $(1914,1916)$ described the formation of an embryonic blastema in which the primordia of the definitive organs originate after the ingestion of the yolk. This blastema is formed through proliferation of the migrating cells, which mostly accumulate on the ventral side of the embryo. The primary embryonic blastema subdivides into three regions: an anterior primordium that gives rise to the cephalic region and the central nervous system; a central primordium associated with the degenerating embryonic pharynx and in which the definitive pharynx and the digestive system will form; and a posterior primordium in which posterior structures, muscles, glands, and eventually the reproductive system, will differentiate (Fig. 4). Several years later, Fulinski put forward the possibility that the embryonic pharynx of planarians is homologous to the blastopore 
of other Platyhelminthes (Fulinski 1938).

Acconci (1919) also studied the fertilization, cleavage and early stages of development in D. lacteum and S. polychroa. Carlé (1935) described for the first time the embryonic development of two land planarians, Geoplana notocelis and Rhynchodemus terrestris, demonstrating that it was similar to that already reported for freshwater species.

\section{Second half of the 20th century: systematization}

The early studies by Seilern-Aspang $(1956,1957)$ characterized the embryonic development of the marine species Procerodes lobata, confirming that all lineages of planarians show similar embryonic traits. In a subsequent report (Seilern-Aspang 1958) the author addressed in great detail the embryogenesis of planarians, and in particular the mechanisms that operate during the formation of the yolk-derived syncytium, cleavage and the organization of the transient yolk-feeding embryo. Based on fine observations of early embryos, the author proposed that the zygote delivers chemotactic substances to attract surrounding yolk cells and stimulate their fusion into a syncytium before cleavage starts. This idea had also been put forward by Acconci (1919), and in 1991 it was again suggested by Sakurai, based on observations of the ultrastructure of the zygote and the yolk cells during these initial stages.

Up to the mid 1950s, the term used to describe the cleavage and formation of the yolk-feeding embryo had been the German phrase BlastomerenAnarchie. However, Seilern-Aspang (1958) attempted to give a mechanistic interpretation of the blastomere movements within the yolk-derived syncytium. He subdivided blastomeres into three different groups: positive, negative and neutral. According to his hypothesis, negative blastomeres are repelled towards the periphery of the yolk-derived syncytium, forming the embryonic epidermis. Meanwhile, positive and neutral blastomeres remain in a central position. Afterwards, positive blastomeres move to the extreme of the syncytium and differentiate into the embryonic pharynx, while neutral blastomeres keep on wandering around, becoming the so-called migratory cells. In this way, the primary yolk-derived syncytium is transformed into a radial embryo, with an axis running through the embryonic pharynx that will be the

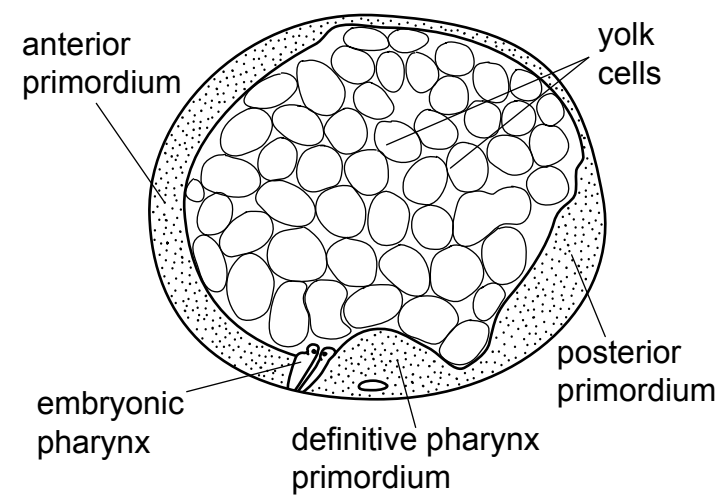

Fig. 4. Formation of the definitive organs from an embryonic blastema. According to Fulinski (1916), definitive organs form from three major blastemas: an anterior primordium, in which the nervous system develops; a central primordium, close to the embryonic pharynx and that gives rise to the definitive pharynx; and a posterior primordium, which forms all the caudal structures. Muscle cells and the parenchyma develop from isolated cells of the three blastemas. future dorsoventral axis of the definitive embryo. This model was the starting point for future studies, in particular those by Koscielski (1964, 1966, 1967).

At the same time, Skaer (1965) dealt with the formation of the definitive epidermis, demonstrating that its origin lies in undifferentiated cells of the embryonic parenchyma that migrate, intercalate into the degenerating embryonic epidermis, and differentiate into adult epidermal cells. This process takes place at two different time points: just after the ingestion of the maternally supplied yolk cells, and simultaneously to the differentiation of the other definitive cell types.

However, the most significant studies were conducted by Albert Le Moigne (1963, 1966, 1969) using the freshwater species Polycelis nigra and Polycelis tenuis. In these, the author addressed the study of planarian embryogenesis using techniques never used before, in particular the transmission electron microscope, which offered new levels of resolution and information. Based on his observations, Le Moigne (1963) systematized planarian embryonic development, subdividing it into seven major stages (Fig. 5). Furthermore, he made relevant contributions to understanding the relationship between embryogenesis and adult regeneration, and the embryonic origin of neoblasts.

Briefly, the stages proposed by Le Moigne $(1963,1966)$ are:

-Stage 1: formation of the yolk-derived syncytium and disperse cleavage. In his opinion, there is no homology between the typical germ layers of other metazoans and the segregation of blastomeres in planarians.

-Stage 2: appearance of the transientorgans (primary epidermis, embryonic pharynx and transitory intestine).

- Stage 3: ingestion of the maternally supplied yolk cells. The yolk-derived syncytium becomes restricted to the periphery of the embryo, forming the so-called germ band. The undifferentiated embryonic cells in this thin layer of syncytium start dividing.

- Stage 4: a transitory pharynx, probably unique to $P$. nigra and $P$. tenuis, is formed at the site occupied by the embryonic pharynx. The definitive cell types (neoblasts, muscle cells, digestive and secretory cells, flame cells, etc.) start to differentiate from the proliferating embryonic cells of the germ band.

-Stage 5: the two cerebral ganglions are formed in the anteriorventral part of the embryo. The definitive pharynx differentiates just above the transitory pharynx, and the posterior digestive branches are discernible.

- Stage 6: the pair of ventral nerve cords start to differentiate in an anteroposterior direction and the eyes become visible.

- Stage 7: maturation of the definitive organs prior to hatching.

This scenario proposed by Le Moigne is currently valid, and can be considered as the first modern description of the divergent development of planarians.

In subsequent years, studies focused on particular aspects of development, such as oogenesis, fertilization and the formation of the eggshell (reviewed in Benazzi and Gremigni 1982). Finally, Ishii and Sakurai (1988), Sakurai and Ishii (1995) and Sakurai (1991) dealt with the formation and replacement of the primary epidermis and the yolk-derived syncytium. These authors suggested that the embryonic epidermis forms by fusion of a group of blastomeres on one side of the syncytium, at the point at which the embryonic pharynx will be formed. This organ was thought to be homologous to the blastopore of other animals, and the expansion of the primary epidermis from this point to wrap the whole 
syncytium to be homologous to gastrulation, through a process known as inverse epiboly.

\section{The study of planarian embryology in the 21st century}

As the study of planarian regeneration experienced renewed interest with the establishment of modern molecular techniques (i.e. in situ hybridization, fluorescent immunohistochemistry, gene knockdown by RNA interference, BrdU labeling of proliferative cells, etc.), which opened up a wide range of new possibilities in the study of this striking phenomenon, the need to apply these new molecular methods to the study of planarian embryonic development, in order to bridge the gap between embryonic and post-embryonic phases of the planarian life cycle, became evident.

The work conducted by Cardona et al., (2005a,b, 2006) meant the entry of planarian embryology into the modern era of molecular developmental biology. By a combination of immunohistochemistry and observations under the optical and electron microscope, their studies offer a detailed description of the embryonic development of the planarian species Schmidtea polychroa, in particular of the early stages of development (Cardona et al., 2006) and the formation of the definitive organs (Cardona et al., 2005a). In this re-evaluation of planarian development, Le Moigne's original stag-

Stage 1
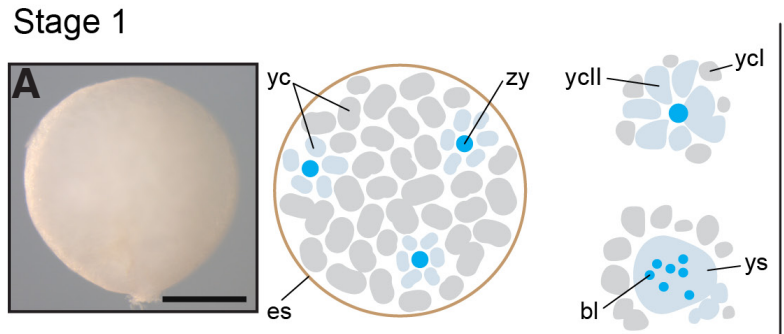

Stage 2
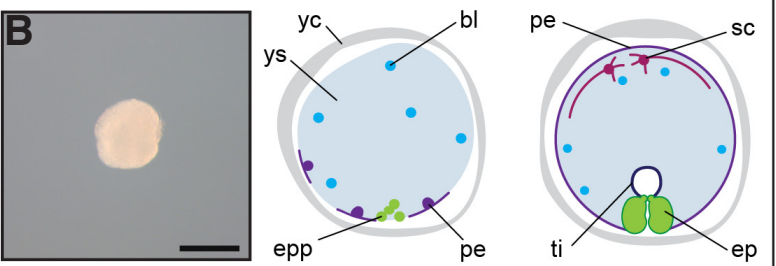

Stage 3
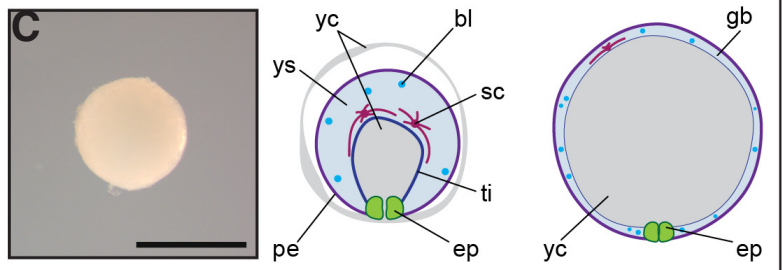

Stage 4
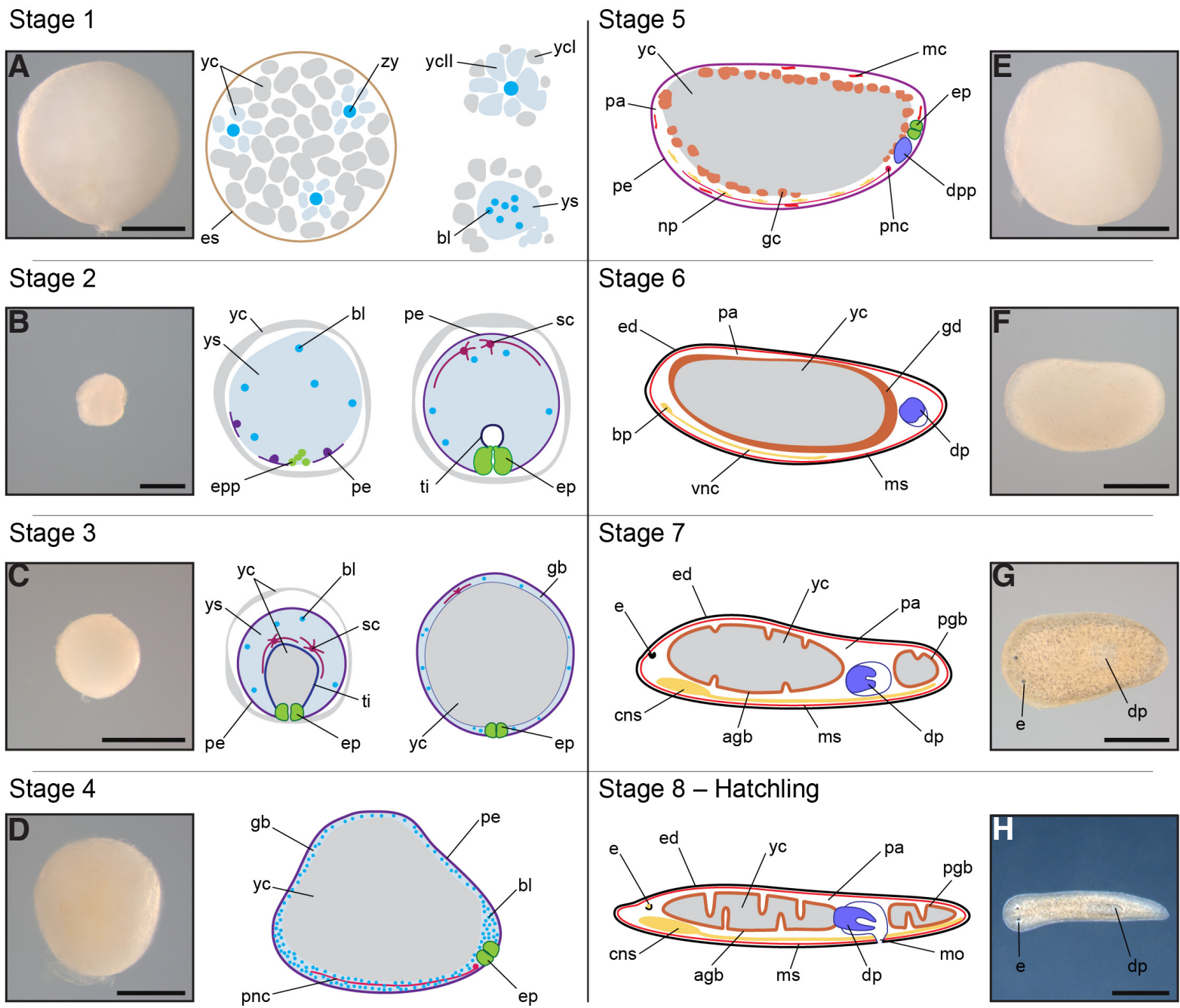

Stage 6

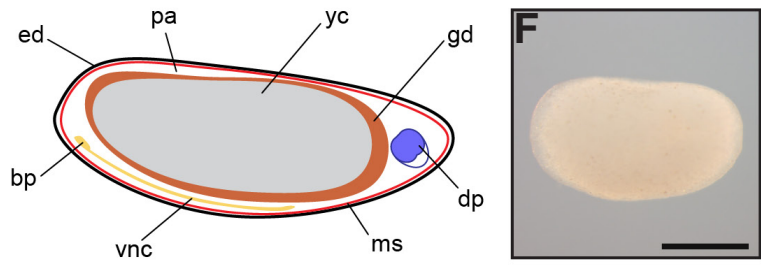

Stage 7

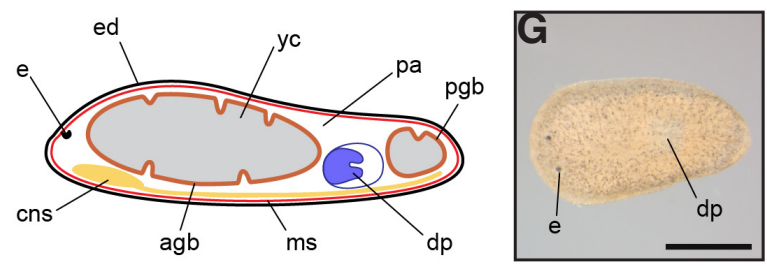

Stage 8 - Hatchling

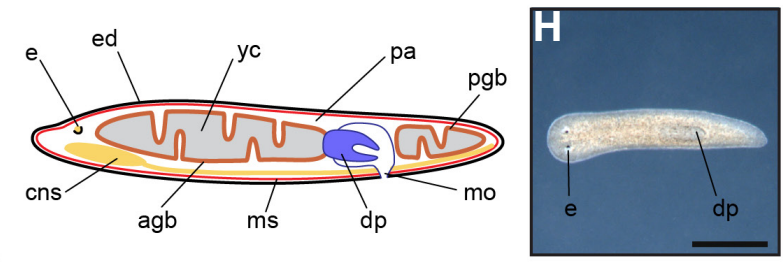

Fig. 5. General overview of planarian embryogenesis. (A-H) Dissected embryos at stage 1, stage 2, stage 3, stage 4, stage 5, stage 6, stage 7 and hatchling, respectively. (A) Mass of yolk cells, inside which yolk-derived syncytium formation and cleavage take place. (B) Early yolk-feeding embryo, with its characteristic transient structures (i.e. primary epidermis, embryonic pharynx, transient intestine and star cells). (C) Due to the ingestion of yolk cells, the embryo grows in size and the initial yolk-derived syncytium becomes restricted to the periphery of the embryo, forming the so called germ band. (D) Blastomeres in the germ band start proliferating, and the pioneer nerve cords become visible. (E) Specification of definitive axial identities and differentiation of the adult cell types starts at stage 5, at the same time as the formation of the definitive pharynx primordium. (F,G), during stages 6 and 7 , the definitive organs arise and develop to acquire the morphology observed in stage 8 embryos and hatchlings (H). Drawings are not to scale. The main illustrated morphological and histological events are based on Le Moigne 1963, Cardona et al., 2005a, Cardona et al., 2006, Martín-Durán et al., 2010 and Martín-Durán and Romero 2011. agb anterior gut branch, bl blastomere, bp brain primordium, cns central nervous system, dp definitive pharynx, dpp definitive pharynx primordium, e eye, ed epidermis, ep embryonic pharynx, epp embryonic pharynx primordium, es eggshell, gb germ band, gc gastrodermal cell, mc muscle cell, mo mouth, ms muscle, np neural precursor, pa parenchyma, pe primary epidermis, pgb posterior gut branch, pnc pioneer nerve cord, sc star cells, ti temporary intestine, vnc ventral nerve cord, yc yolk cells, ycl type I yolk cells, ycll type II yolk cells, ys yolk syncytium, zy zygote. In (F-H) anterior is to the left. Scale bars: (A, C-G) $500 \mu \mathrm{m}$; (B) $250 \mu \mathrm{m}$; (H) $1 \mathrm{~mm}$. 
ing criteria (Le Moigne 1963) were adapted to the staging system proposed by Hartenstein and Ehlers (2000), which had been successfully applied to the embryonic development of other groups of Platyhelminthes, and thus planarian embryogenesis was divided into eight stages (Fig. 6).

Most of the observations made by Cardona et al., (2005a, 2006) confirmed previous reports on the embryonic development of Schmidtea polychroa and other triclads. However, the use of specific molecular markers (i.e. antibodies against specific neural populations or muscle cells, such as serotonin, FMRF-amide or myosin heavy chain) allowed them to thoroughly follow the appearance of specific cell types and tissues. In this respect, the description of the formation of the nervous system was a significant contribution. As early as in stage 2 embryos, a pair of large multipolar cells, known as star cells, appear at the interface between the embryonic epidermis and the syncytial yolk layer (Cardona et al., 2005a). As the embryo ingests the yolk, these cells internalize and associate with the growing transitory intestine. Based mainly on their morphology and immunoreactivity with acetylated-tubulin, tyrosinated-tubulin and serotonin, these cells were interpreted as being the primary nervous system, possibly involved in the control of the movements of the embryo required for the ingestion of the maternally supplied yolk cells.

Like other transitory structures in these early stages of development, these star cells disappear with the formation of the definitive organs. The formation of a definitive nervous system seems to be associated with the appearance of a pair of nerve fibers that run from the degenerating embryonic pharynx towards the opposite pole of the embryo. Known as pioneer nerve cords, they occupy the future ventral side of the embryo on top of which the definitive nervous system will be built during stages 6 and 7 . Unlike the situation described by Le Moigne (1963), the central nervous system develops more or less simultaneously along the anteroposterior axis, through differentiation of regularly spaced concentrations of immunoreactive FMRF-amide neural cells (Cardona et al., 2005a). By stage 7, the anteriormost clusters of cells form the small neuropil

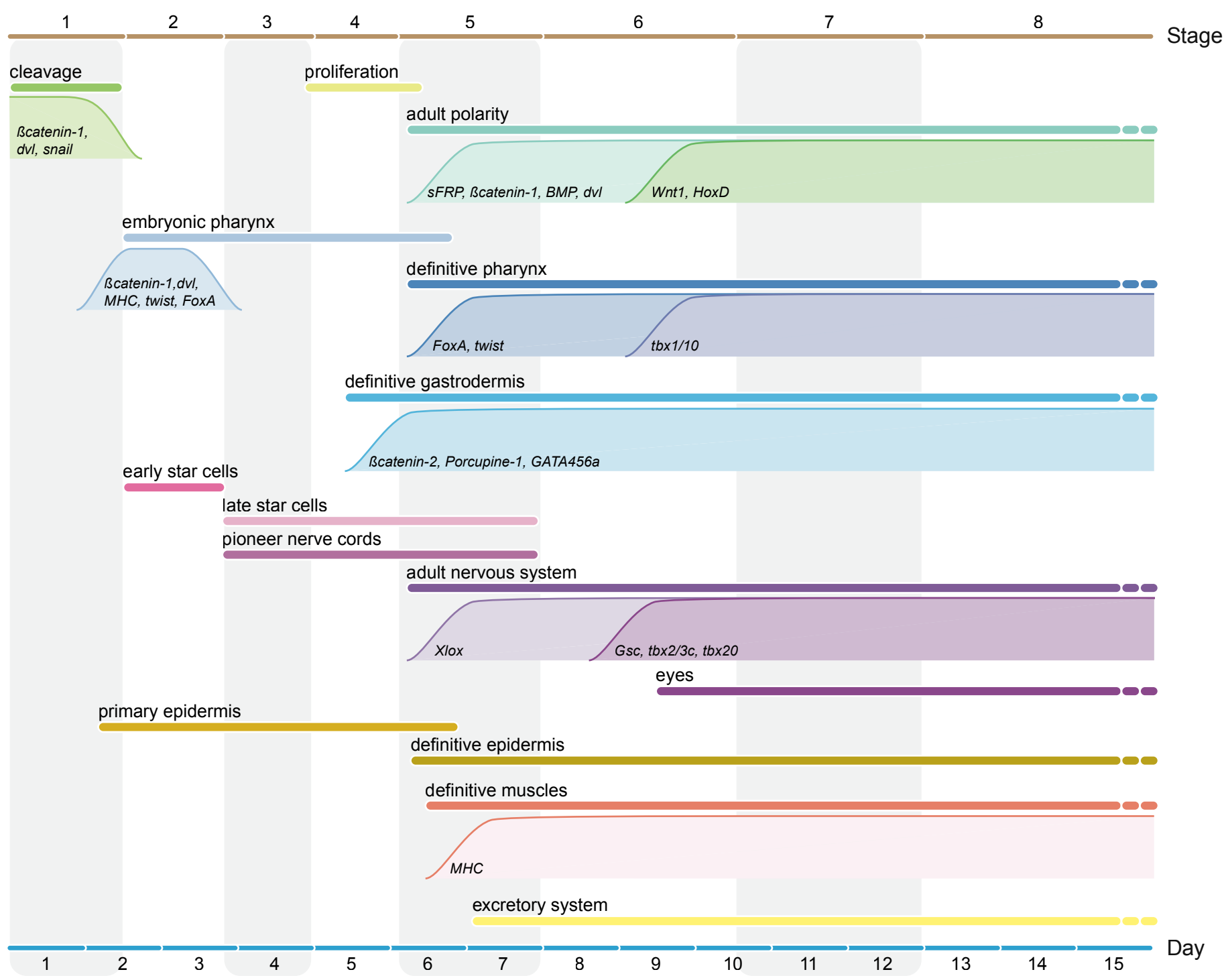

Fig. 6. Overview of planarian embryonic development. Summary of major developmental events (colored bars) and associated gene expression (colored curves) with respect to stages and days of embryogenesis after egg capsule deposition (at $20^{\circ} \mathrm{C}$ ). The chart is based on Cardona et al., $2005 \mathrm{a}$, 2006; Martín-Durán et al., 2010 and Martín-Durán and Romero 2011. 
that gives rise to the definitive bilobed brain.

In addition to morphological and molecular descriptions, the work conducted by Cardona et al., (2005a, 2006) resulted in one of the most striking interpretations of planarian embryogenesis. The development of transient structures (embryonic pharynx, primary epidermis, star cells) was viewed as being part of a cryptic larva (without a free-living phase) required to ingest the yolk material supplied by the mother within the embryonic capsule. The authors suggested that this period of development may have evolved as a consequence of selective pressure to ingest a limited shared amount of embryonic nutrients, ultimately required to accomplish successful development. Whatever their evolutionary origin, the idea of planarians as indirect developers was firmly argued for Cardona et al., (2006), thus supporting alternative, usually neglected, views (Fulinski 1916, Seilern-Aspang 1958, Koscielski 1967).

\section{Gene expression patterns and a comparative approach to studying planarian embryogenesis}

With the optimization of in situ hybridization protocols to visualize the expression of particular genes either in whole-mount embryos or in paraffin sections (Cardona et al., 2005b, Martín-Durán et al., 2010), certain developmental questions that have always attracted attention could be considered from a comparative and evolutionary point of view. The recognition of ancient similarity in patterning mechanisms among distantly related organisms allows the direct comparison of developmental processes, providing new data for understanding metazoan ontogeny and phylogeny.

The work by Solana et al., (2009) and Solana and Romero (2009) dealt with the relationship between blastomeres and neoblasts and the origin of the latter during the embryogenesis of $S$. polychroa. The expression of conserved stem cell markers such as vasa-like gene $A(v \lg A)$ and tudor-1 (tud-1), demonstrated that those blastomeres that do not contribute to the formation of any transient structure in the yolk-feeding embryo remain in an undifferentiated state during yolk ingestion (stages 2-4). As development proceeds and the embryo acquires its definitive morphology, the expression of these genes progressively changes to that observed in juveniles and adults, suggesting that it is during these stages that neoblasts are specified, as proposed by Le Moigne (1966).

In a recent paper (Martín-Durán et al., 2010), a comparative analysis of conserved genes involved in the establishment of the metazoan body plan was used to address how axial identities and different cell fates are specified during planarian embryogenesis. The expression of core components of the canonical Wnt pathway (Bcatenin-1, Wnt1, sFRP, dishevelled) and BMP pathway (bmp), known to control the anteroposterior and dorsoventral patterning in adult planarians (Cebrià et al., 2010), shows that the asymmetric expression of some of these genes along the bilateral axes of the organism appears from stage 5 onwards, as the embryo acquires its worm-like shape, the transient yolk-feeding organs are reabsorbed, and the definitive structures are formed (Fig. 6). During early stages, these genes are either not expressed (e.g. bmp) or show no clear asymmetric expression in the embryo, with the exception of $\beta$ catenin-1, which becomes restricted to the embryonic pharynx after cleavage. These data led the authors to suggest that the definitive polarity is established late in development, at stage 5 , while early stages either feature different mechanisms of axial identity or, more likely, lack true axiality and thus the radiality of the yolk-feeding embryo. In this respect and despite the divergence of the initial developmental stages, conserved mechanisms of tissue segregation and specification can still be discerned. Genes such as twist and foxA conserve their expression associated with the formation of the muscle and foregut, respectively (Martín-Durán et al., 2010).

Asimilar comparative approach was used to study the embryonic development of the digestive system (Martín-Durán and Romero 2011). Despite the evolutionary significance of the features exhibited by this organ in planarians and other flatworms (i.e. single gut opening and, therefore, blind gastrodermis), until that point it had been one of the least studied due to difficulties in specifically staining and visualizing gastrodermal cells in planarian embryos. A combination of histological studies and gene expression analysis demonstrated that gastrodermal cells are specified during stage 4-5, in a more or less diffuse pattern, eventually giving rise to a thin endodermal epithelium that surrounds the ingested yolk. After hatching, the gastrodermal cells ingest the nutrients, acquiring a mature morphology during this process. The process of embryonic patterning in the digestive system was studied by means of conserved endodermal and anteroposterior gut markers (foxA, GATA456, goosecoid, paraHox genes and T-box genes) (Fig. 6). Based on their expression patterns, the authors concluded that the blind gut of planarians lacks discernible anteroposterior regionalization in the foregut, midgut and hindgut, but conserves the conserved molecular boundary between the pharynx and gastrodermis displayed by foxA and GATA456 genes in some spiralians.

\section{Towards a deeper understanding of planarian embryol- ogy}

The systematic analysis of expression patterns of master developmental control genes has consolidated many of the classic concepts about planarian embryogenesis that were based on morphological studies (Solana et al., 2009, Solana and Romero 2009, Martín-Durán et al., 2010, Martín-Durán and Romero 2011). The involvement of most of these genes in conserved metazoan developmental events leads to fundamental questions being considered from a completely new point of view. When and how is axial polarity defined during the divergent development of planarians? Does real gastrulation that defines the major tissue fates take place? How is the transient organization related to the definitive body plan? In the following, we address these primary questions and develop a comprehensive scenario for planarian embryogenesis in an attempt to unify concepts and link this peculiar mode of development with the better known ancestral spiralian cleavage and adult planarian regeneration.

\section{Establishment of axial identities}

The work by Martín-Durán et al., (2010) demonstrated that the asymmetric expression of genes controlling the axial identities along the bilateral axes occurs at stage 5, when the specification of most of the definitive cell types and organs begins (Le Moigne 1963, Cardona et al., 2005a, Martín-Durán and Romero 2011). This observation prompts one to question how the transient yolkfeeding embryo is organized and whether the definitive axiality is already defined in this early phase, although using mechanisms other than those observed in hatchlings and adults. In our opinion, two features of planarian embryogenesis must be taken into consideration: the distinctive disperse cleavage, which distinguishes 
planarians from all other canonical spiralian developers, and the presence of a transient independent embryonic organization (i.e. the yolk-feeding embryo).

Spiralian development relies heavily on maternal determinants and cell-cell interactions to specify the different cell lineages and axial organizers during cleavage (Nielsen 2010). In some taxa (some annelids and molluscs, sipunculids), the axial organizer (the $\mathrm{D}$ quadrant and its descendants) is already defined as early as in the four-cell embryo. This is accomplished by the transmission of maternal determinants present in the zygote to one of the four cells through asymmetric cell divisions and/or the formation of a polar lobe (van Dam et al., 1982). These embryos are commonly called unequal-cleaving spiralians. However, many of the spiralian lineages are equal-cleaving, and therefore, early cleavage does not lead to specification of the D quadrant. In these embryos, it is the process of cell-cell communication that sets up the embryonic organizer at the 16-32 cell stage, during which one of the vegetal blastomeres contacts the animal micromeres and becomes specified as the D quadrant (van den Biggelaar and Guerrier, 1979). In both cases, the molecules involved remain elusive. Regardless of the type of cleavage, the descendants of the D quadrant will occupy a dorso-posterior position in the embryo, and will guide the cell lineages of the A, B and C quadrants to form the left, ventroanterior and right regions of the embryo, respectively (Freeman and Lundelius 1992). Are these events conserved in the disperse equal-cleavage observed in planarians?

Despite the fact that some studies have shown a primary polarity in the oocyte (Stevens 1904, Benazzi 1950, Anderson and Johann 1958), the best sign of maternal determinants is the presence of high levels of transcripts for genes like $\beta$ catenin- 1 in freshly laid egg capsules (Martín-Durán et al., 2010). Although probable, their localization in the zygote needs to be proven. On the other hand, the existence of stereotypic cell-cell interactions between certain blastomeres is much more unlikely. The disperse cleavage exhibited by planarian embryos seems to imply weak and intermittent interactions between cells, which probably vary from one embryo to another. In canonical spiralian embryos the absence of inductive signals between cells (or the removal of the polar lobe in unequal-cleaving spiralians) leads to the formation of a radialized embryo with an oral-aboral axis, which lacks the axial organizer, but gastrulates normally and thus forms the ectoderm, endoderm and a stomodeum (Wilson 1904, Martindale et al., 1985). In these embryos, an unusual number of blastomeres remain undifferentiated, due to the absence of an organizer. This situation shows a strikingly resemblance to that in early planarian embryos.

All these data suggest that alternative mechanisms that establish the bilateral axes during early cleavage in planarian embryos are not strictly necessary. Instead, it is tempting to propose that the deviations in the canonical spiral cleavage found in this lineage are responsible by themselves for organizing the radial yolk-feeding embryo. The asymmetric inheritance of certain maternal determinants would be sufficient to trigger the specification of the early lineages found in the transient embryo (i.e. epidermal cells, muscle and endothelial cells of the embryonic pharynx, etc.), whereas the absence of an axial organizer would lead to the formation of the observed radial organization and keep most of the blastomeres undifferentiated and wandering around the yolk-derived syncytium. In this scenario, the ingestion of the maternally supplied yolk cells would activate the mechanisms of axial patterning, transforming the primary radial stage into a bilateral embryo.

\section{Segregation of the germ layers}

Whether or not true gastrulation occurs has been one of the fundamental questions in planarian embryology. Since the work of Stevens (1904), authors have tended to accept the absence of real gastrulation movements during early development. However, has this key embryonic event been lost in the lineage leading to planarians? What do we understand by "gastrulation"?

According to Gilbert (1985), gastrulation is the developmental event in which cell movements lead to the formation of a multilayered embryo with its basic body plan. This process is, therefore, tightly linked to the specification of the endoderm and the development of the gut cavity (Technau and Scholz 2003). Although the cell movements responsible for the appearance of this internal germ layer are highly diverse across metazoans, establishment of the gastrulation site and the endodermal cell fate seems to be fairly conserved, the canonical Wnt pathway being a master regulator of these processes (Martindale and Hejnol 2009). In addition to the endoderm, an additional germ layer, the mesoderm, is specified during early development in bilaterians, although not necessarily during gastrulation (Technau and Scholz 2003). In our opinion, the question regarding the occurrence of true gastrulation in planarian embryogenesis should focus on whether the events that characterize every known gastrulation (i.e. cell migration, formation of a multilayered embryo and establishment of the basic body plan) are present in planarians, and not on if it is possible to recognize a stereotypic gastrula stage.

In this respect, cell motility is by itself one of the most obvious feature of early planarian development. Disperse cleavage is characterized by the detachment of the blastomeres, which no longer form a compact morula, but instead move and diffuse across the yolk-derived syncytium. Despite the anarchic situation that might be apparent at first sight, defined groups of blastomeres are set up after reaching a certain number of cells: those that form the primary epidermis, the primordium of the embryonic pharynx, and the blastomeres that remain undifferentiated in the yolk syncytium. The appearance of these three major groups is related both to a change in the position of cells in the syncytium and also to the activation of a specific molecular profile: the expression of $\beta$ catenin- 1 is restricted to those cells forming the embryonic pharynx, in which mechanisms of mesoderm differentiation (expression of twist and myosin heavy chain) and endoderm/gut specification (expression of foxA) are present (Martín-Durán et al., 2010). At the same time, those blastomeres that do not contribute to the formation of any transient structure keep expressing stem cell markers, such as vasa and tudor (Solana et al., 2009, Solana and Romero 2009).

The formation of the embryonic pharynx also implies the development of a primary cavity (transitory intestine) inside the yolk-derived syncytium (Metschnikoff 1883, lijima 1884, Hallez 1887, Martín-Durán et al., 2010). This small cavity will gather the ingested yolk cells and is, in fact, the future gut cavity of the definitive embryo and adult (Martín-Durán and Romero 2011). It is thus not strange that early embryologists named this transient intestine the archenteron (Hallez 1887). Finally, disperse cleavage and the segregation of different groups of blastomeres are directly related to the establishment of the primary embryonic organization, or the yolk-feeding embryo, which as mentioned above represents the "scaffold" on which the definitive embryo will develop after yolk 
ingestion.

Taking into account all these arguments, we believe that early stages of planarian development (stages 1 and 2) meet the minimum requisites for considering them as a true divergent mode of gastrulation (Martín-Durán et al., 2010). Nevertheless, the idiosyncrasy of planarian embryos makes their gastrulation, a mandatory step in metazoan development, diverge from the idealized view that many of us have based on the study of the most common animal models.

\section{Organogenesis}

Historically, the study of planarian embryogenesis has focused on early stages, since they are the most striking. Although Bardeen (1902) began to address the formation of the definitive cell types during late development, it was not until Le Moigne $(1963,1966)$ and more recently Cardona et al., (2005a,b) and Martín-Durán and Romero (2011) that a more accurate picture of the appearance of the final organs was achieved. As these studies demonstrate, the development of organs like the digestive system, the musculature, the epidermis and the nervous system takes place diffusely throughout the germ band, rather than in three discrete ventral blastemas as proposed by Fulinski (1916). Despite the fact that the first traces of cell differentiation are observed in stage 5 embryos, the expression of genes involved in the specification of these cell types can already be detected during stage 3-4 (Cardona et al., 2005b, Martín-Durán etal., 2010, Martín-Durán and Romero 2011). This observation together with the fact that the definitive axial identities seem to be specified during these same stages reinforces the notion of this phase of development as a sort of metamorphosis, during which a large part of the primary embryonic architecture is remodeled or replaced by the definitive body plan.

\section{Embryonic development and regeneration}

The study of the embryonic development of planarians is of great importance to better understand the cellular and molecular mechanisms involved in adult planarian regeneration. The first comparison between these two processes was made by Hallez (1887), working with $D$. lacteum. Based on his observations, he concluded that both events were roughly similar, especially at the organismic level. Later studies demonstrated the presence of similar stages in the formation of organs like the definitive pharynx or the eyes (Le Moigne 1969, Cardona 2005a, Martín-Durán and Romero 2011, Martín-Durán et al., 2012). However, adult planarian regeneration is not merely a recapitulation of embryonic development and several differences should be noted. First, comparisons between the two events should be limited to stages 4-5 onwards of embryonic development, since this is the time when equivalent organs and structures are formed. Taking this into account, clear similarities, both at the cellular and the molecular level, between the embryonic development of the definitive organs and their adult regeneration can be traced. Likewise, the mechanisms controlling the establishment of the definitive body plan and polarity in embryos and regenerants seem to be similar. Second, the starting point for each of these two processes is completely different. While the whole definitive embryo forms from a diffuse set of undifferentiated cells located in the germ band, the regeneration of a structure must involve the identification of the missing body part, which then has to be integrated into a preexisting body pattern. In this way, regeneration has to be much more regulative than embryogenesis in planarians. Therefore, not only does planarian regeneration rely on the presence of pluripotent stem cells (neoblasts) or the maintenance of patterning mechanisms in the adult, but also on mechanisms required to evaluate what has to be regenerated, which are apparently absent during normal embryogenesis.

\section{Conclusions and future directions}

The article has reviewed the most relevant work dealing with planarian embryogenesis. When considered from a historical point of view, it is evident that several questions have recurrently intrigued researchers working with planarian embryos. How did disperse cleavage evolve and how is it controlled? Is it homologous to true gastrulation? And therefore, is there true segregation of germ layers? How and when are the bilateral axes established in embryonic development? How are embryogenesis and regeneration connected in planarians? How do the definitive organs develop? Adopting a comparative approach, using both the gene expression patterns of evolutionarily conserved developmental genes and morphology, has revealed similarities between adult planarian regeneration and late stages of development, as well as between the ancestral quartet-spiral cleavage and the divergent early stages of embryogenesis. Nevertheless, efforts should be made to develop functional methodologies in order to validate many of the hypotheses raised and to increase our knowledge of this interesting divergent mode of development to the level of other emerging embryonic systems and adult planarian regeneration.

\section{Acknowledgements}

We thank M. Vila-Farré and members of the laboratories of F. Cebrià and E. Saló for support and valuable comments on this manuscript. JMM-D was an FPU fellow from the MICINN (Ministerio de Ciencia e Innovación), Spain. FM was an APIF fellow from the University of Barcelona, Spain. This work was supported by MEC BFU-2007-63209, Spain, to RR.

\section{References}

ACCONCI C (1919). Osservazioni sullo sviluppo delle planarie d'acqua dolce. Boll Ist Zool R Univ Palermo 1:49-76.

ANDERSON JM, JOHANN JC (1958). Some aspects of reproductive biology in the freshwater triclad turbellarian, Cura foremanii. Biol Bull 115:375-482.

BARDEEN CR (1902). Embryonic and regenerative development in planarians. Biol Bull 3:262-288.

BENAZZI M (1950). Ginogenesi in tricladi di acqua dolce. Chromosoma 3:474-482

BENAZZI M, GREMIGNI V (1982). Developmental biology of Triclad turbellarians. In Developmental biology of freshwater invertebrates (Ed. F. W. Harrison and R. R. Cowden). Alan R. Liss, New York, pp. 151-211.

CARDONAA, HARTENSTEIN V, ROMERO R (2005a). The embryonic development of the triclad Schmidtea polychroa. Dev Genes Evol 215:109-131.

CARDONA A, FERNÁNDEZ-RODRÍGUEZ J, SOLANA J, ROMERO R (2005b). An in situ hybdridization protocol for planarian embryos: monitoring myosin heavy chain gene expression. Dev Genes Evol 215:482-488.

CARDONA A, HARTENSTEIN V, ROMEROR (2006). Early embryogenesis of planaria: a cryptic larva feeding on maternal resources. Dev Genes Evol 216:667-681.

CARLÉ R (1935). Beiträge zur embryologie der landplanarien. I. Frühentwicklung, bau und junktion des embryonalpharynx. Zoomorphology 29:527-558.

CEBRIÀ F, ADELLT, SALÓ E (2010). Regenerative medicine: lessons from planarians. In Stem cell, regenerative medicine and cancer (Ed. S. R. Singh). Nova Science Publishers, Hauppauge, pp. 29-68.

CURTIS WC (1902). The life story, the normal fission and the reproductive organs of Planaria maculata. Proc Boston Soc Nat Hist 30:515-559.

CURTIS WC (1905). The location of the permanent pharynx in the planarian embryo. 
Zool Anz 29:169-175.

FREEMAN G, LUNDELIUS JW (1992). Evolutionary implications of the mode of D quadrant specification in coelomates with spiral cleavage. J evol Biol 5:205-247.

FULINSKI B (1914). Die entwiklungesgichte von Dendrocoelum lacteum Oerst I Teil: Die erste entwiklungsphase vom ei bis zur embryonalpharynx bildung. Bull Acad Sci Cracovie, Cl des Sci Math Nat, Ser B 8/9:147-190.

FULINSKI B (1916). Die keimblätterbildung bei Dendrocoelum lacteum Oerst. Zool Anz 47:380-400.

FULINSKIB (1938). Zur embryonalpharynxfrage der Trikladiden. Zool Polon2:185-207.

GALLENI L, GREMIGNI V (1982). Fertilization, development and parental care in Turbellaria. In Reproductive biology of invertebrates (Eds. K.G. Adiyodi and R.G. Adiyodi). Vol. 4. J. Wiley, Chichester, pp. 63-89.

GILBERT SF (1985). Developmental Biology. Sinauer Associates, Inc., Sunderland, Massachusetts.

GIRIBET G, DISTEL DL, POLZ M, STERRER W, WHEELER WC (2000). Tripoblastic relationships with emphasis on the acoelomates and the position of Gnathostomulida, Cycliophora, Plathelminthes, and Chaetognatha: a combined approach of 18S rDNA sequences and morphology. Syst Biol 49:539-562.

HARTENSTEIN V, EHLERS U (2000). The embryonic development of the rhabdocoel flatworm Mesostoma lingua (Abildgaard, 1789). Dev Genes Evol 210:399-415.

HALLEZ P (1887). Embryogénie des Dendrocoeles d'eau douce. Mem Soc Sci Lille 16:1-107.

HEJNOL A (2010). A twist in time- The evolution of spiral cleavage in the light of animal phylogeny. Integr Comp Biol 50:695-706.

HEJNOL A, OBST M, STAMATAKIS A, OTT M, ROUSE GW, EDGECOMBE GD, MARTINEZ P, BAGUÑÀ J, BAILLY X, JONDELIUS U, WIENS M, MÜLLER WEG, SEAVEREC, WHEELER WC, MARTINDALE MQ, GIRIBET G, DUNN CW (2009). Assessing the root of bilaterian animals with scalable phylogenomic methods. Proc Biol Sci B 276:4261-4270.

IIJIMA I (1884). Untersuchungen über den Bau un die Entwiklungesgichte der Süßwasser-Drendocoelen (Tricladen). $Z$ wiss Zool 40:359-464.

ISHII S, SAKURAI T (1988). Scanning and transmission electron microscopic observations on epidermal development in the embryo of the freshwater triclad, Bdellocephala brunnea. Fortschr Zool 36:291-295.

KNAPPERT B (1865). Bijdragen tot de ontwikkelingsgeschiedenis der zoetwaterplanarien. Natuurk Verh uitg dh Prov Utrechtsch Genootschap v Kunstenen Wetens.

KNAPPERT B (1866). Embryogénie des planaries d'eau douce. Arch neerl $d$ sci ex et nat (Haarlem) 1:271-272.

KÖLLIKER A (1846). Ueber die contractilen Zellen der Planarienembryonen. Arch Naturgesch 12:291-295.

KOSCIELSKI B (1964). Polyembryony in Dendrocoelum lacteum O. F. Müller. J Embryol exp Morph 12:633-636.

KOSCIELSKIB (1966). Cytological and cytochemical investigations on the embryonic development of Dendrocoelum lacteum O. F. Müller. Zool Pol 16:83-102.

KOSCIELSKI B (1967). Experimental studies on embryonic development of Dendrocoelum lacteum O. F. Müller. Experientia 23:212-214.

LE MOIGNE A (1963). Etude du développement embryonnaire de Polycelis nigra (Turbellarié, Triclade). Bull Soc Zool Fr 88:403-422.

LE MOIGNE A (1966). Etude du développement embryonnaire et recherches sur les cellules de régénération chez l'embryon de la Planaire Polycelis nigra (Turbellarié, Triclade). J Embryol exp Morph 15:39-60.

LE MOIGNE A (1969). Etude du développement et de la régénération embryonnaires de Polycelis nigra (Ehr.) et Polycelis tenuis (lijima), Turbellariés Triclades. Ann Embryol 2:51-69.
LITTLEWOOD DTJ (2008). Platyhelminth systematics and the emergence of new characters. Parasite 15:333-341.

MARTÍN-DURÁN JM, AMAYA E, ROMERO R (2010). Germ layer specification and axial patterning in the embryonic development of the freshwater planarian Schmidtea polychroa. Dev Biol 340:145-158.

MARTÍN-DURÁN JM, ROMEROR (2011). Evolutionary implications of morphogenesis and molecular patterning of the blind gut in the planarian Schmidtea polychroa. Dev Biol 352:164-176.

MARTÍN-DURÁN JM, MONJO F, ROMERO R (2012). Morphological and molecular development of the eyes during embryogenesis of the freshwater planarian Schmidtea polychroa. Dev Genes Evol 222:45-54.

MARTINDALE MQ, DOE CQ, MORRILL JB (1985). The role of animal-vegeta interaction with respect to the determination of dorsoventral polarity in the equalcleaving spiralian, Lymnaea palustris. Wilhelm Roux Arch Dev Biol 194:281-295

MARTINDALE MQ, HEJNOL A (2009). A developmental perspective: changes in the position of the blastopore during bilaterian evolution. Dev Cell 17:162-174.

MATTIESEN E (1904). Ein beitrag zur embryologie der Süsswasserdendrocoelen. $Z$ wiss Zool 77:274-361.

METSCHNIKOFF E (1883). Die embryologie von Planaria polychroa. $Z$ wiss Zool 38:331-354

NIELSEN C (2010). Some aspects of spiralian development. Acta Zoologica91:20-28.

SAKURAI T (1991). An electron-microscopic study of syncytium formation during early embryonic development of the freshwater planarian Bdellocephala brunnea. Hydrobiologia 227:113-118.

SAKURAI T, ISHII S (1995). An ultrastructural study of primary epidermis formation in Bdellocephala brunnea (Turbellaria; Tricladida). Invertebr Reprod Dev 28:77-85.

SEILERN-ASPANG F (1956). Frühentwicklung einer mariner triclade (Procerodes lobata O. Schmidt). Wilhelm Roux'Arch 148:589-595.

SEILERN-ASPANG F (1957). Polyembryonie als abnorme entwicklung bei Procerodes lobata O. Schmidt (Turbellaria). Zool Anz 159:187-193.

SEILERN-ASPANG F (1958). Entwicklungsge schichtliche studien an paludicolen tricladen. Wilhelm Roux Arch Entwickl Mech Org 150:425-480.

SHIBATA N, ROUHANA L, AGATA K (2010). Cellular and molecular dissection of pluripotent adult somatic stem cells in planarians. Dev Growth Differ 52:27-41.

SOLANA J, LASKO P, ROMERO R (2009). Spoltud- 1 is a chromatid body component required for planarian long-term stem cell self-renewal. Dev Biol 328:410-421.

SOLANA J, ROMERO R (2009). Spolvlg-A is a DDX3/PL10-related DEAD-box RNA helicase expressed in blastomeres and embryonic cells in planarian embryonic development. Int J Biol Sci 5:64-73.

STEVENS NM (1904). On the germ cells and the embryology of Planaria simplicissima. Proc Acad Nat Sci Philadelphia 56:208-220.

TECHNAU U, SCHOLZ CB (2003). Origin and evolution of endoderm and mesoderm. Int J Dev Biol 47:531-539.

VAN DAM WI, DOHMEN MR, VERDONK NH (1982). Localization of morphogenetic determinants in a special cytoplasm present in the polar lobe of Bithynia tentaculata. Wilhelm Roux Arch Dev Biol 191:371-377.

VAN DEN BIGGELAAR JAM, GUERRIER P (1979). Dorsoventral polarity and mesentoblast determination as concomitant results of cellular interactions in the mollusk Patella vulgata. Dev Biol 68:462-471.

WESTBLAD E (1948). Studien über skandinavische Turbellaria Acoela. V. Ark Zool 41A:1-82.

WILSON EB (1904). Experimental studies on germinal localization. I. The germ regions in the egg of Dentalium. J Exp Zool 1:1-72. 


\section{Further Related Reading, published previously in the Int. J. Dev. Biol.}

Planarian regeneration: achievements and future directions after $\mathbf{2 0}$ years of research Emili Saló, Josep F. Abril, Teresa Adell, Francesc Cebriá, Kay Eckelt, Enrique FernándezTaboada, Mette Handberg-Thorsager, Marta Iglesias, M Dolores Molina and Gustavo Rodríguez-Esteban

Int. J. Dev. Biol. (2009) 53: 1317-1327

From Planarians to Mammals - the many faces of regeneration

Jerzy Moraczewski, Karolina Archacka, Edyta Brzoska, Maria-Anna Ciemerych, Iwona Grabowska, Katarzyna Janczyk-Ilach, Wladyslawa Streminska and Malgorzata Zimowska Int. J. Dev. Biol. (2008) 52: 219-227

Characterization of novel genes expressed specifically in the sexual organs of the planarian Dugesia ryukyuensis

Sumitaka Hase, Emiko Kashiwagi, Kazuya Kobayashi, Motonori Hoshi and Midori Matsumoto Int. J. Dev. Biol. (2007) 51: 345-349

Planarian pharynx regeneration revealed by the expression of myosin heavy chain-A Tomoko Sakai, Kentaro Kato, Kenji Watanabe and Hidefumi Orii Int. J. Dev. Biol. (2002) 46: 329-332

Disto-proximal regional determination and intercalary regeneration in planarians, revealed by retinoic acid induced disruption of regeneration

$\mathrm{R}$ Romero and $\mathrm{D}$ Bueno

Int. J. Dev. Biol. (2001) 45: 669-673

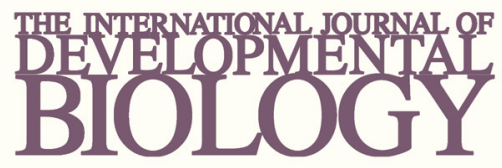

Volume 54 Nos. 6/7
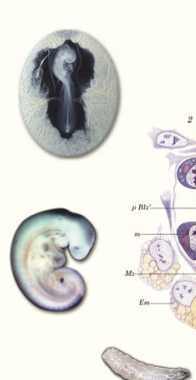

Developmental Hematopoiesis
Special Issue
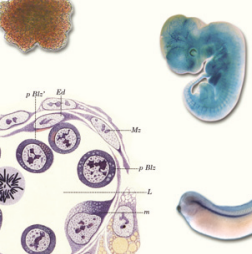

(-)

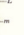

(1)
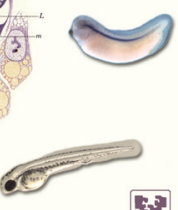

?
5 yr ISI Impact Factor $(2010)=2.961$

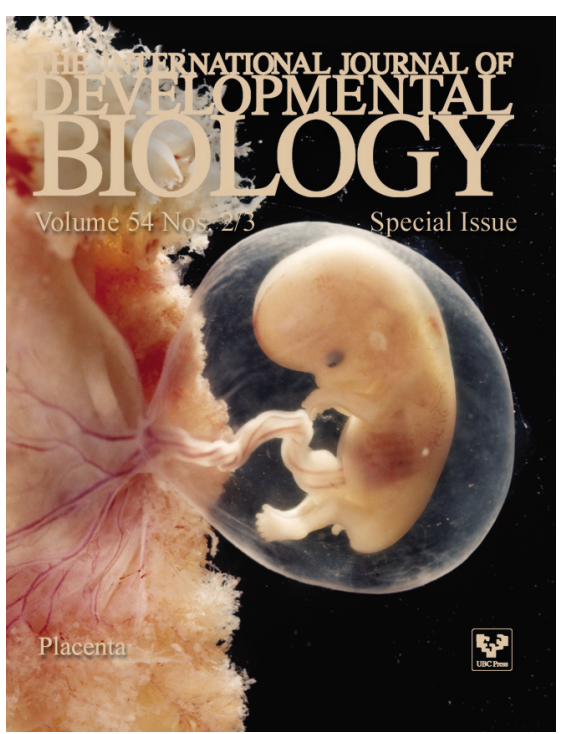

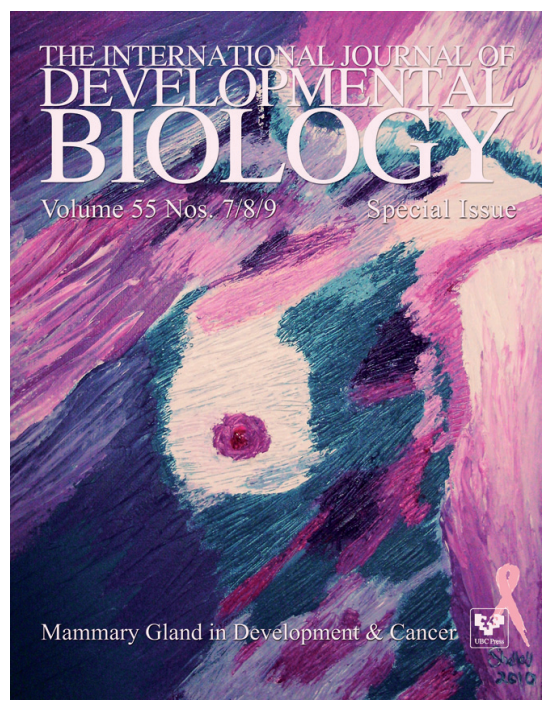

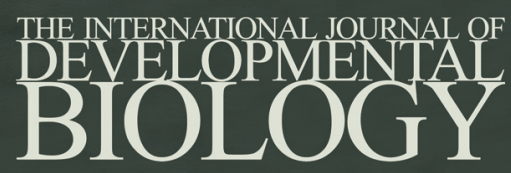

Volume 55 Nos. $4 / 5$

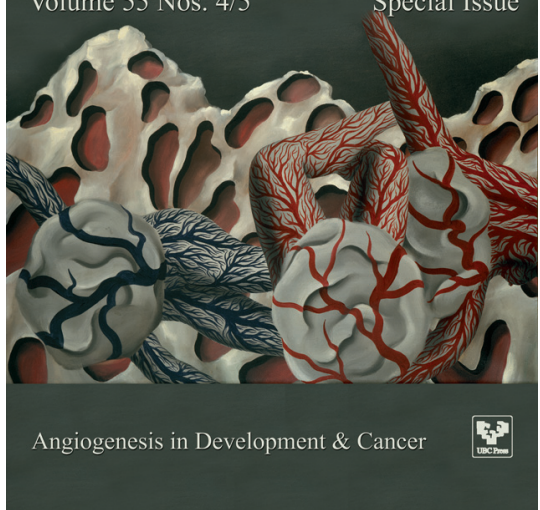

